\title{
An eddy-covariance system with an innovative vortex intake for measuring carbon dioxide and water fluxes of ecosystems
}

\author{
Jingyong Ma ${ }^{1,2}$, Tianshan Zha ${ }^{1,2}$, Xin Jia ${ }^{1,2}$, Steve Sargent ${ }^{3}$, Rex Burgon ${ }^{3}$, Charles P.-A. Bourque ${ }^{4}$, Xinhua Zhou ${ }^{3}$, \\ Peng Liu ${ }^{1,2}$, Yujie Bai ${ }^{1,2}$, and Yajuan $\mathbf{W u}^{1,2}$ \\ ${ }^{1}$ School of Soil and Water Conservation, Beijing Forestry University, Beijing, China \\ ${ }^{2}$ Beijing Engineering Research Center of Soil and Water Conservation, Beijing Forestry University, Beijing, China \\ ${ }^{3}$ Campbell Scientific, Inc., Logan UT, USA \\ ${ }^{4}$ Faculty of Forestry and Environmental Management, 28 Dineen Drive, University of New Brunswick, \\ Fredericton, New Brunswick, Canada \\ Correspondence to: Tianshan Zha (tianshanzha@bjfu.edu.cn)
}

Received: 26 August 2016 - Discussion started: 1 November 2016

Revised: 1 March 2017 - Accepted: 9 March 2017 - Published: 30 March 2017

\begin{abstract}
Closed-path eddy-covariance (EC) systems are used to monitor exchanges of trace gases (e.g., carbon dioxide $\left[\mathrm{CO}_{2}\right]$, water vapor $\left[\mathrm{H}_{2} \mathrm{O}\right]$, nitrous oxide and methane) between the atmosphere and biosphere. Traditional ECintake systems are equipped with inline filters to prevent airborne dust particulate from contaminating the optical windows of the sample cell which causes measurement degradation. The inline filter should have a fine pore size (1 to $20 \mu \mathrm{m}$ is common) to adequately protect the optics and a large filtration surface area to extend the time before it clogs. However, the filter must also have minimal internal volume to preserve good frequency response. This paper reports test results of the field performance of an EC system (EC155, Campbell Scientific, Inc., Logan Utah, USA) with a prototype vortex intake replacing the inline filter of a traditional EC system. The vortex-intake design is based on fluid dynamics theory. An air sample is drawn into the vortex chamber, where it spins in a vortex flow. The initially homogenous flow is separated when particle momentum forces heavier particles to the periphery of the chamber, leaving a much cleaner airstream at the center. Clean air (75\% of total flow) is drawn from the center of the vortex chamber, through a tube, to the sample cell where it is exposed to the optical windows of the gas analyzer. The remaining $25 \%$ of the flow carries the heavier dust particles away through a separate bypass tube. An EC155 system measured $\mathrm{CO}_{2}$ and $\mathrm{H}_{2} \mathrm{O}$ fluxes in two urban-forest ecosystems in the megalopolis of Beijing, China. These sites present a challenge for
\end{abstract}

EC measurements because of the generally poor air quality which has high concentrations of suspended particulate. The closed-path EC system with vortex intake significantly reduced maintenance requirements by preserving optical signal strength and sample-cell pressure within acceptable ranges for much longer periods. The system with vortex intake also maintained an excellent frequency response. For example, at the Badaling site, the amount of system downtime attributed solely to clogged filters was reduced from $26 \%$ with traditional inline filters to $0 \%$ with the prototype vortex intake. The use of a vortex intake could extend the geographical applicability of the EC technique in ecology and allow investigators to acquire more accurate and continuous measurements of trace-gas fluxes in a wider range of ecosystems.

\section{Introduction}

Eddy-covariance (EC) technology provides an opportunity to evaluate the fluxes of energy, momentum, water vapor, carbon dioxide and other scalars between the earth's surface and the turbulent atmosphere (Aubinet et al., 2016; Baldocchi, 2003; Montgomery, 1948). The technology has been widely used in ecosystem studies worldwide, including forests, grasslands, agricultural lands and wetlands (e.g., Mitchell et al., 2015; Shoemaker et al., 2015; Wang et al., 2015; Zha et al., 2010). However, the technology's use in many urban green-space ecosystems has been challenging 
because of polluted air that contaminates the optical windows of the gas analyzer. Optical signal strength is reduced and gas concentration measurements degrade as dust and debris are deposited on the optical windows of the analyzer. This problem occurs in both open-path and closed-path systems. Using intakes with inline filters in closed-path systems can help keep the analyzer's windows free of debris for a longer time. However, in environments with extremely dirty air, inline filters clog quickly - often in a matter of just days - and require frequent replacement (Bressi et al., 2013; Hasheminassab et al., 2014; Villalobos et al., 2015; Yu et al., 2013). Dirty sample air can also contaminate other parts of the EC system, leading to underestimated fluxes and data gaps (Jia et al., 2013; Xie et al., 2015).

With urbanization, urban green spaces are expanding commensurately (Pataki et al., 2006). Urban green spaces are playing a progressively more important role in the study of ecosystem carbon balances worldwide (McHale et al., 2007). To address the challenges associated with urban settings, an improved EC system capable of operating in polluted, urban environments is needed to monitor carbon dynamics in urban areas and to evaluate green-space ecosystem response to environmental change (Pataki et al., 2006; Xie et al., 2015). Additionally, such improvements should benefit measurements in other landscapes, particularly for closed-path methane or nitrous oxide analyzers, which often have stringent filtration requirements to keep multi-pass sample cells clean. Filter clogging has been noted as a maintenance issue over a fen (Peltola et al., 2013), agricultural fields and wetlands (Detto et al., 2011), a dairy farm (Kroon et al., 2007) and a forest (Eugster et al., 2007).

The traditional approach for maintaining good trace-gas concentration measurements in a closed-path EC system is to use an inline filter to clean sampled air. The inline filter in the original EC155 design is based on a sintered stainless steel disk, with $1 / 16$-inch thick $\times 1$-inch diameter of either 20 or $40 \mu \mathrm{m}$ porosity, mounted in a rubber rain cap. In practice, the porosity of the filter is chosen for the conditions of the specific site to minimize the frequency of replacement. Fine-pore filters keep the analyzer windows clean for a longer time, but clog more quickly. The gas analyzer sample-cell windows must be cleaned when optical signal strength diminishes to $80 \%$, and the filter must be replaced when the pressure drop exceeds $7 \mathrm{kPa}$. Ideally, the filter pore size is chosen such that the windows become dirty at approximately the same time that the filter clogs, meaning only a single visit to the site. Inline filters are a functional solution for filtering particulate-filled air sufficiently to maintain good measurements. However, the maintenance labor can be significant, and either a clogged filter or dirty windows can disrupt measurements until the analyzer receives maintenance. This maintenance can be required frequently - weekly or even daily - in conditions with high particulate matter in the ambient air.

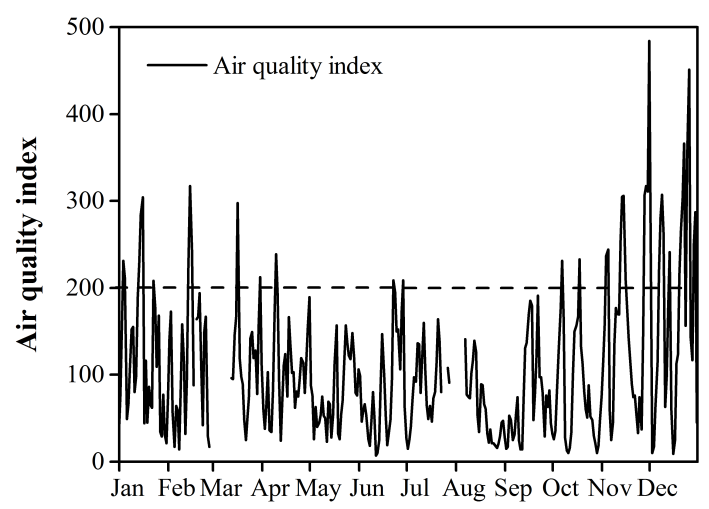

Time (days)

Figure 1. Daily mean air quality index during 2015 in Beijing, China. Air quality index is stratified into six categories: 0-50 for low, 51-100 for low to mild, 101-150 for mild, 151-200 for moderate, 201-300 for severe and > 300 for serious air pollution levels.

To avoid the frequent replacement of filters in EC systems deployed in urban environments, an advanced EC system with vortex intake (United States Patent No. 9217 692) has been recently developed by Campbell Scientific, Inc., Logan, UT, USA. The vortex intake eliminates the need for an inline filter upstream of the gas analyzer. The first implementation of this design is a prototype that can be clipped onto an existing EC155 analyzer, replacing the inline filter (this study). Burgon et al. (2016) reported laboratory test results for a production version of the EC155 with a vortex intake. A nitrous oxide EC system with vortex intake was described by Somers and Sargent (2015), and a long-term trial of this system began in a cornfield in southern Ontario, Canada, in May 2015 (Brown et al., 2015).

This study introduces vortex-intake sampling and demonstrates its field performance with in situ measurements collected in two urban green-space areas within the megalopolis of Beijing, China. The goals for the new design were to (1) minimize system maintenance, (2) reduce system downtime due to clogged filters and (3) maintain high-frequency response. The objective of this field test was to compare the performance of a prototype vortex-intake sampling system with that of a traditional system fitted with an inline filter.

\section{Materials and methods}

\subsection{Site description and data collection period}

The study sites are located in Beijing Olympic Forest Park $\left(40.02^{\circ} \mathrm{N}, 116.38^{\circ} \mathrm{E}, 51 \mathrm{~m}\right.$ above mean sea level, AMSL) and Badaling Tree Farm $\left(40.37^{\circ} \mathrm{N}, 115.94^{\circ} \mathrm{E}\right.$, $535 \mathrm{~m}$ a.m.s.l.), Beijing, China. Beijing's air quality is generally poor, with high concentrations of suspended particulate in the atmosphere (Fig. 1) and hazy conditions, at times with visibility $<10 \mathrm{~km}$. Haze is a common problem, particularly 
during the winter and spring, stemming from a variety of contributing factors including home heating, traffic congestion, industrial activity, stable synoptic conditions and surrounding mountainous topography (e.g., Yang et al., 2015; Zhang et al., 2016; Zheng et al., 2015).

The Olympic Forest Park is the largest urban forest park in Asia, with an area of 680 ha and vegetation coverage of about $90 \%$. The site is an ecological conservation and restoration area. The site is dominated by Pinus tabulaeformis L. Other species include Platycladus orientalis, Sophora japonica L., Fraxinus chinensis and Ginkgo biloba, with an understory of Iris tectorum and Dianthus chinensis. All trees were tagged and identified by species and trees with a diameter at breast height $(\mathrm{DBH})>3 \mathrm{~cm}$ are being assessed annually. Stand density was 210 trees ha ${ }^{-1}$, with a mean tree height of $7.7 \mathrm{~m}$ and a mean DBH of $20 \mathrm{~cm}$. Cover ratio of trees to shrubs was about $7: 3$. The shrubs were Prunus davidiana, Amygdalus triloba, Swida alba and Syzygium aromaticum, with a mean height of $2.8 \mathrm{~m}$ (Xie et al., 2015).

The Badaling Tree Farm is about $60 \mathrm{~km}$ from the downtown core of Beijing. Local terrain is generally flat and uniform. The study site is composed of Acer truncatum, Koelreuteria paniculata, Fraxinus bungeana, Ailanthus altissima and Pinus tabuliformis. Stand density was 975 trees ha ${ }^{-1}$, with a mean tree height of $4 \mathrm{~m}$ and a mean DBH of $4.7 \mathrm{~cm}$. The study site has a sparse herbaceous cover with no welldefined understory canopy (Jia et al., 2013).

Data presented in this study were acquired from field deployment of two EC systems; one at each of the two sites described above. Both systems were deployed in 2011 with the original inline filter intakes. Data with the inline filter design were collected from January 2011 to July 2014 at the Olympic Park and from January 2011 to September 2014 at Badaling Farm. Both EC systems were switched to the vortex intake in 2014. Data with vortex intakes were acquired from July 2014 to December 2015 at Olympic Park and from September 2014 to December 2015 at the Badaling Farm.

\subsection{Instrument description}

An EC155 (model EC155, Campbell Scientific, Inc. Logan, UT, USA) is an in situ, closed-path, mid-infrared absorption gas analyzer (IRGA) that measures molar mixing ratios of $\mathrm{CO}_{2}$ and $\mathrm{H}_{2} \mathrm{O}$ at high frequency. The original EC155 analyzer includes a heated intake tube, inline filter and rain cap (Fig. 2a). The modified EC155 system includes a prototype vortex chamber and rain cap in place of the original filter and rain cap (Fig. 2b).

The vortex intake is a small, lightweight device with no moving parts, and requires no chemicals to clean the sample air. Its simple design makes it essentially maintenance free. The vortex assembly (Fig. 2b) consists of a rain cap and inlet nozzle, a vortex chamber and two outlet ports. Schematics of both systems are shown in Fig. 3. Unlike a filter, the vortex intake design is based on fluid and particle dynam- (a)
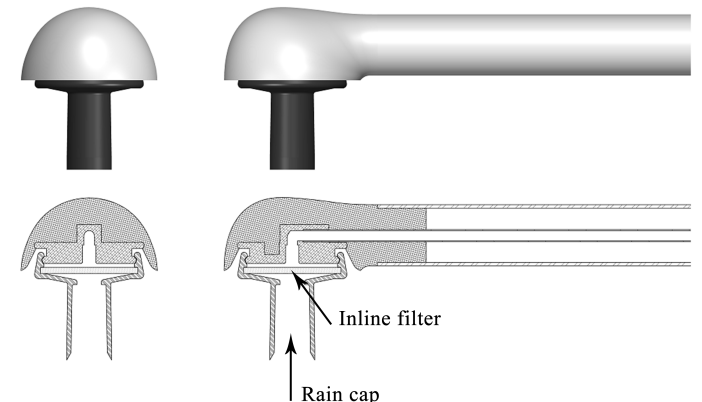

(b)
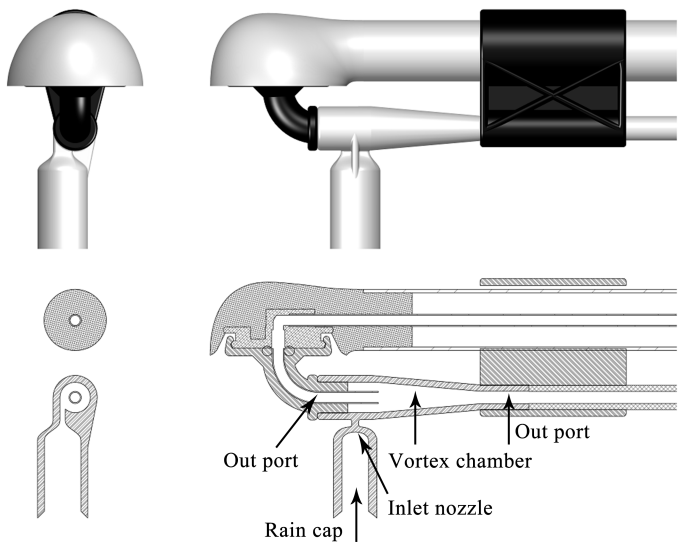

Figure 2. EC155 sample intakes: (a) original inline filter and (b) prototype vortex intake (source: Campbell Scientific Inc., Logan UT, USA).

ics. Sampled air enters the vortex chamber through a tangent port to induce rotational flow. Entrained dust-particle motion is governed by centrifugal force (inertia), aerodynamic drag and chamber wall impact forces. The high rotational speed of the vortex flow provides the larger and heavier (relative to air) dust particles with greater centrifugal force, keeping them close to the chamber wall and leaving the air in the center of the vortex free of dust. Clean sample air flows from the vortex center through a tube to the EC155 sample cell. The dust particles in the air close to the wall of the vortex chamber are pulled out through the bypass tube. The dirty air passes through a relatively large $(12 \mathrm{~mL}$ internal volume $)$ filter (9922-05-DQ, Parker Hannifin Corp., Mayfield Heights $\mathrm{OH}, \mathrm{USA})$ with moderate porosity $(25 \mu \mathrm{m})$ that requires only infrequent replacement due to clogging. The filter protects a flow-control orifice that balances the airflow split such that 6 is sampled and $2 \mathrm{~L} \mathrm{~min}^{-1}$ is bypassed. The two flows rejoin downstream of the analyzer, then go to the single, low-power ( $5 \mathrm{~W}$ ) vacuum pump. In contrast, the EC55 with the inline filter has slightly higher flow through the analyzer $\left(7 \mathrm{~L} \mathrm{~min}^{-1}\right)$. Burgon et al. (2016) measured the frequency response of the EC155 with the inline filter and with the production vortex design using the impulse response method (Sargent, 2012), showing that the cutoff frequency is proportional to flow, as expected: $5.1 \mathrm{~Hz}$ for the original design at $7 \mathrm{~L} \mathrm{~min}^{-1}$ and $4.3 \mathrm{~Hz}$ for the vortex design at $6 \mathrm{~L} \mathrm{~min}^{-1}$. 
(a)

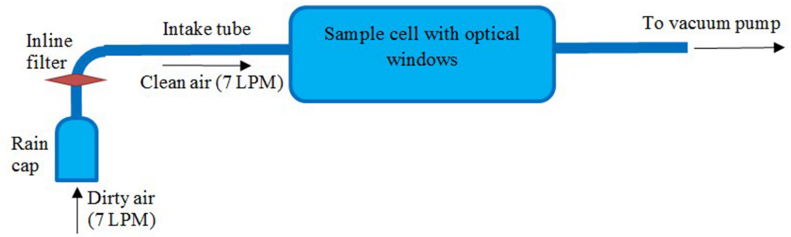

(b)

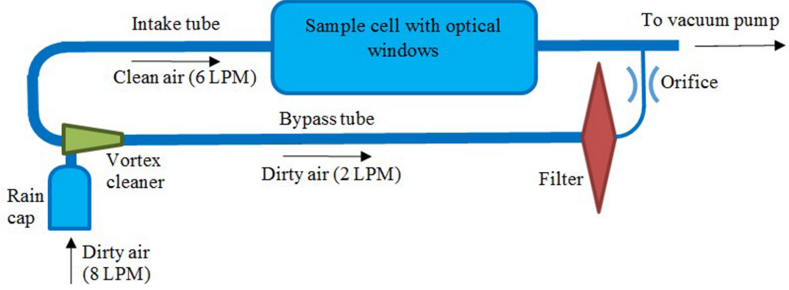

Figure 3. Schematics of EC155 sampling systems with (a) an original inline filter and (b) vortex intake.

For flux determination (covariances), high-frequency wind velocity measurements are needed. Wind velocities are acquired with a fast-response, three-dimensional sonic anemometer (CSAT3A; Campbell Scientific, Inc. Logan, UT, USA). Spatial separation between the EC155 intake and the CSAT3A sample volume is $15.6 \mathrm{~cm}$.

At Olympic Forest Park, a $12 \mathrm{~m}$-tall tower is surrounded by uniform forest cover with a homogeneous fetch of about $600 \mathrm{~m}$ in all directions. The EC instruments were mounted on the tower at a height of $11.5 \mathrm{~m}$ from the ground. The EC instrumentation was installed similarly at the Badaling Tree Farm. All flux-related data were collected at $10 \mathrm{~Hz}$ using a CR3000 data logger (Campbell Scientific, Inc. Logan, UT, USA). Half-hourly turbulent fluxes were calculated from the covariance between the fluctuations in the vertical wind speed and the scalar quantities (Aubinet et al., 2000). Sonic temperature was corrected for changes in atmospheric humidity and pressure (Schotanus et al., 1983).

\subsection{Field tests}

Attenuation of high-frequency fluctuations is one of the systematic errors in EC measurements, and it is especially important to address it when trace-gas concentrations are measured with a closed-path analyzer (Aubinet et al., 2000). The frequency response of a system is defined as a ratio of its output to its input as a function of the signal frequency. In an ideal system, the value would be one at all frequencies. In a real system, fluctuations in $\mathrm{CO}_{2}$ or $\mathrm{H}_{2} \mathrm{O}$ tend to be damped at higher frequencies due to adding a rain cap, filter and intake tubing to a gas sampling system (Aubinet et al., 2016). Measuring the frequency response quantifies the loss of highfrequency information so that a correction may be applied.

With this in mind, the frequency response of a closed-path EC system with vortex intake is compared to one with an inline filter. In situ field measurement of system frequency response is challenging because the true signal inputs (scalar

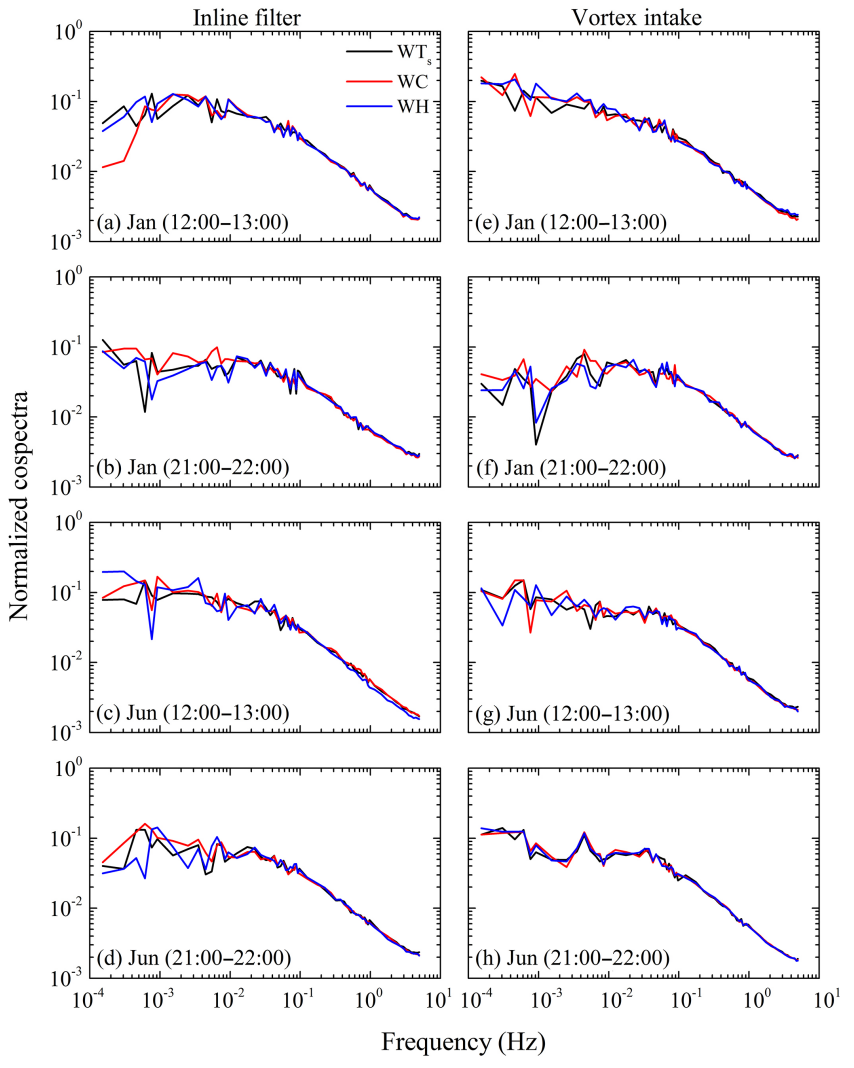

Figure 4. Normalized cospectra of the EC system (EC155) equipped with inline filter (a-d) and vortex intake (e-h). $W T_{\mathrm{s}}$, WC and WH are cospectra of vertical wind velocity with sonic temperature, $\mathrm{CO}_{2}$ and $\mathrm{H}_{2} \mathrm{O}$. Cospectra are calculated from highfrequency data at $10 \mathrm{~Hz}$ obtained from the Olympic Park. Data points in the figure are binned averages from means of a $1 \mathrm{~h}$ period (12:00-13:00 and 21:00-22:00 Beijing Standard Time) for each day in January $\left(\mathbf{a ~ C O}\right.$ flux value was $1.88 \mu \mathrm{mol} \mathrm{s}{ }^{-1} \mathrm{~m}^{-2}$; b $\mathrm{CO}_{2}$ flux value was $\left.0.7 \mu \mathrm{mol} \mathrm{s}^{-1} \mathrm{~m}^{-2}\right)$, June $\left(\mathrm{c} \mathrm{CO}_{2}\right.$ flux value was $-15.39 \mu \mathrm{mol} \mathrm{s}^{-1} \mathrm{~m}^{-2}$; $\mathbf{d ~ C O} 2$ flux value was $4.58 \mu \mathrm{mol} \mathrm{s}^{-1} \mathrm{~m}^{-2}$ ) 2014 for the inline filter-based EC measurements, and in January (e $\mathrm{CO}_{2}$ flux value was $-0.25 \mu \mathrm{mols} \mathrm{s}^{-1} \mathrm{~m}^{-2}$; f $\mathrm{CO}_{2}$ flux value was $0.59 \mu \mathrm{mol} \mathrm{s}{ }^{-1} \mathrm{~m}^{-2}$ ), June $(\mathrm{g} \mathrm{CO}$ flux value was $-11.17 \mu \mathrm{mol} \mathrm{s}^{-1} \mathrm{~m}^{-2} ; \mathbf{h ~ C O}$ flux value was $1.25 \mu \mathrm{mol} \mathrm{s}{ }^{-1} \mathrm{~m}^{-2}$ ) 2015 for the vortex-intake measurements.

variables) are not known a priori. However, it can be evaluated by comparing the cospectra of the vertical component of wind with fluctuations of sonic temperature $\left(W T_{\mathrm{s}}\right.$, where $W$ denotes the vertical component of wind and $T_{\mathrm{S}}$ the sonic temperature) to the cospectra of the vertical component of wind with fluctuations of $\mathrm{CO}_{2}$ (WC, where $\mathrm{C}$ denotes the mixing ratio of $\left.\mathrm{CO}_{2}\right)$ and $\mathrm{H}_{2} \mathrm{O}\left(\mathrm{WH}\right.$, where $\mathrm{H}$ denotes $\mathrm{H}_{2} \mathrm{O}$ mixing ratio). Analysis of cospectra are based on data from the Olympic Forest Park over $1 \mathrm{~h}$ periods (12:00-13:00 and 21:00-22:00 Beijing Standard Time) averaged daily for the months of January (high incidence of haze) and June (low incidence of haze) 2014 for the inline filter-based EC measurements, and January (high incidence of haze) and June (low 


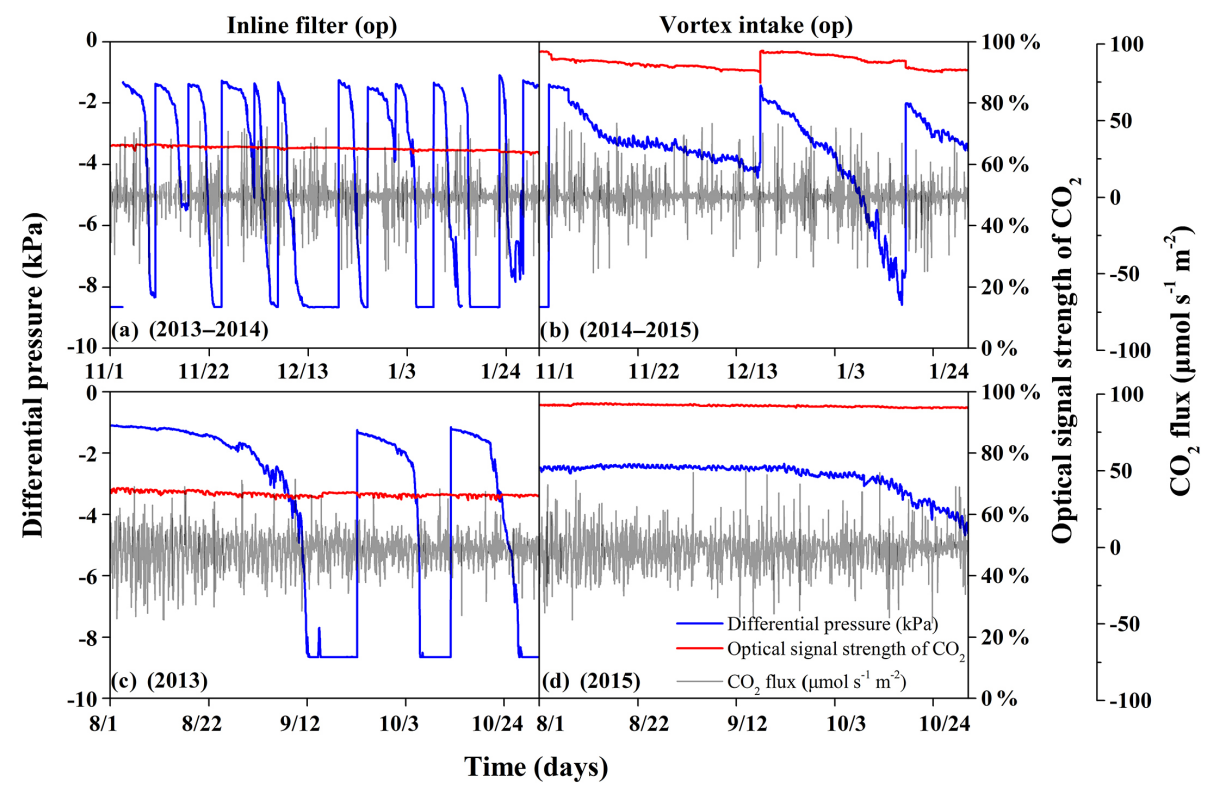

Figure 5. Differential pressure (blue line), optical signal strength of $\mathrm{CO}_{2}$ (red line) and $\mathrm{CO}_{2}$ flux (gray line) of the EC system (EC155) equipped with vortex intake as compared to an inline filter at the Olympic Park (op); panels (a) and (b) are for periods of very hazy conditions, whereas panels (c) and (d) are for periods of low haze.

incidence of haze) 2015 for the vortex-intake-based measurements. A fast Fourier transform was applied for each variable's time series, consisting of about 36000 data points.

Decreases in sample-cell differential pressure and $\mathrm{CO}_{2}$ optical signal strength indicate when the inline filter needs to be replaced and the optical windows cleaned. Clogged filters can induce substantial pressure drops (Aubinet et al., 2016). Generally, the pressure drop in the original intake assembly is approximately $2.5 \mathrm{kPa}$ at $7 \mathrm{LPM}$ flow without filter. The filter adds approximately $1 \mathrm{kPa}$ pressure drop when it is clean. This pressure drop will increase as the filter clogs. The filter should be replaced before the differential pressure reaches $\pm 7 \mathrm{kPa}$. Additionally, the windows of the analyzer should be cleaned when the optical signal strength of $\mathrm{CO}_{2}$ drops below $80 \%$ of the original value.

\section{Results and discussion}

\subsection{Frequency response}

Due to damping of high-frequency signals in closed-path systems, gas cospectra commonly exhibit reduced response at high frequencies, causing flux loss (Burba et al., 2010; Leuning and King, 1992). Brach and Lee (Brach et al., 1981; Lee et al., 2004) found that the cospectrum of vertical wind velocity with sonic temperature $\left(W T_{\mathrm{s}}\right)$ is often very close to the ideal cospectrum. In field experiments, $W T_{\mathrm{s}}$ is often used as a standard to evaluate whether there is a high-frequency loss for other measured scalars. To examine the effect of a vortex intake, spectral analysis was applied to the measure- ments collected in situ. Ensemble cospectra of vertical wind velocity with $\mathrm{CO}_{2}(\mathrm{WC})$ and $\mathrm{H}_{2} \mathrm{O}$ vapor $(\mathrm{WH})$ were compared to those for the sonic temperature $\left(W T_{\mathrm{S}}\right)$ for both the inline filter and vortex intake in different periods (Fig. 4). The normalized cospectra for both systems were consistent at all frequencies, with no significant difference $(P>0.05)$; thus the frequency response of the EC155 sampling system with either the inline filter or a vortex intake could not be distinguished from that of the sonic anemometer. However, the frequency response of a sonic anemometer depends on horizontal wind speed, and the results in Fig. 4 are based on data with relatively low wind speed $\left(0.3\right.$ to $\left.1.5 \mathrm{~m} \mathrm{~s}^{-1}\right)$. The corresponding cutoff frequencies for the sonic anemometer are 2 to $10 \mathrm{~Hz}$ (Massman, 2000), which bracket the EC155 cutoff frequencies measured in the laboratory $(5.1$ and $4.3 \mathrm{~Hz}$ for the inline filter and vortex intake, respectively, Burgon et al., 2016).

Closed-path IRGAs with long inlet tubes often show additional high-frequency damping for $\mathrm{H}_{2} \mathrm{O}$ due to sorption effects (Goulden et al., 1996; Laubach and Teichmann, 1996; Leuning and Judd, 1996), which is not apparent in Fig. 4. The EC155 has a very short intake tube $(0.6 \mathrm{~m})$, which has been shown to reduce this effect (Burba et al., 2010; Clement et al., 2009). Ibrom et al. (2007) showed that this sorption effect increased with higher relative humidity, but Runkle et al. (2012) showed a weaker dependence on relative humidity at higher temperatures. Figure 4 shows results with relative humidity of $\leq 50 \%$ for all cases except summer evenings (Fig. 4d and h), which had higher relative humidity $(65 \%)$, but also warm temperatures $\left(27^{\circ} \mathrm{C}\right)$. The water sorption ef- 
Table 1. Summary of field maintenance notes for the EC155 with vortex intake compared to the EC155 with an inline filter at Olympic Park (op) and Badaling Farm (bd), Beijing, China. The time range includes periods of both high and low incidence of haze. Clog period is the number of days for the differential pressure to reach $\pm 7 \mathrm{kPa}$ after installing a new filter.

\begin{tabular}{|c|c|c|c|c|c|c|c|c|c|}
\hline Site & $\begin{array}{r}\text { Start } \\
\text { data }\end{array}$ & $\begin{array}{l}\text { End } \\
\text { data }\end{array}$ & Intake & $\begin{array}{l}\text { Time } \\
\text { range } \\
\text { (days) }\end{array}$ & $\begin{array}{r}\text { Number } \\
\text { of maintenance } \\
\text { services }\end{array}$ & $\begin{array}{r}\text { Downtime } \\
\text { from clogged } \\
\text { intake (days) }\end{array}$ & $\begin{array}{r}\text { Downtime } \\
\text { percent }\end{array}$ & $\begin{array}{r}\text { Minimum } \\
\text { clog period } \\
\text { (days) }\end{array}$ & $\begin{array}{r}\text { Average } \\
\text { clog period } \\
\text { (days) }\end{array}$ \\
\hline \multirow[t]{4}{*}{ op } & $1 / 11 / 13$ & $31 / 1 / 14$ & Inline filter & 184 & 15 & 57 & $31 \%$ & 1 & 6 \\
\hline & $1 / 8 / 13$ & $31 / 10 / 13$ & & & & & & & \\
\hline & $1 / 11 / 14$ & $31 / 1 / 15$ & Vortex & 184 & 4 & 9 & $5 \%$ & 21 & 46 \\
\hline & $1 / 8 / 15$ & $31 / 10 / 15$ & & & & & & & \\
\hline \multirow[t]{4}{*}{ bd } & $1 / 11 / 12$ & $31 / 12 / 12$ & Inline filter & 122 & 7 & 32 & $26 \%$ & 9 & 20 \\
\hline & $1 / 9 / 12$ & $31 / 10 / 12$ & & & & & & & \\
\hline & $1 / 11 / 14$ & $31 / 12 / 14$ & Vortex & 122 & 0 & 0 & $0 \%$ & $>122$ & $>122$ \\
\hline & $1 / 9 / 15$ & $31 / 10 / 15$ & & & & & & & \\
\hline
\end{tabular}

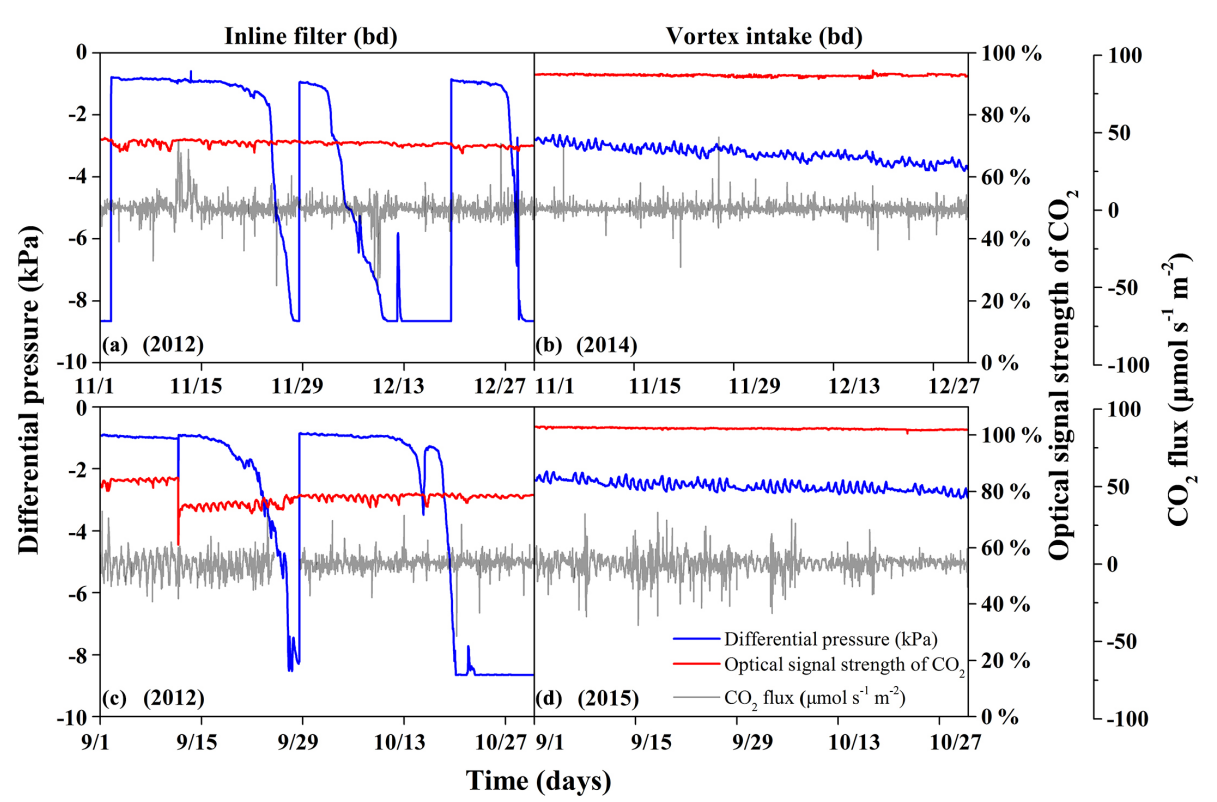

Figure 6. Differential pressure (blue line), optical signal strength of $\mathrm{CO}_{2}$ (red line) and $\mathrm{CO}_{2}$ flux (gray line) of the EC system (EC155) equipped with vortex intake as compared to an inline filter at the Badaling Farm (bd); panels (a) and (b) are for periods of very hazy conditions, whereas panels (c) and (d) are for periods of low haze.

fect is expected to be relatively small for these dry and warm conditions.

\subsection{Differential pressure and optical signal strength of $\mathrm{CO}_{2}$}

Air quality at Olympic Park was mostly poor during the measurement periods, being worse in winter than in summer. To verify performance of the vortex intake, we chose periods of high and low incidence of haze to compare the differential pressure and optical signal strength of $\mathrm{CO}_{2}$. Figure 5 shows time series of 3 months for each case. The differential pressure decreased as the inline filter clogged (Fig. 5a and c), quickly exceeding the range of the pressure sensor $( \pm 7 \mathrm{kPa})$, invalidating data until the filter could be replaced. The differential pressure with the vortex intake was much more stable than with the inline filter. Over a period of 3 months, the differential pressure with vortex intake exceeded the pressure sensor range once during very hazy conditions (Fig. 5b). The optical signal strength of $\mathrm{CO}_{2}$ with the vortex intake remained above $90 \%$, indicating that the optical windows remained free of debris for a substantially longer time than with the inline filter.

At the Badaling Farm site, we also chose periods of high and low incidence of haze to compare differential pressure and optical signal strength of $\mathrm{CO}_{2}$. As shown by the differential pressure in Fig. 6a and c, the inline filter clogged multiple times in a period of 2 months resulting in large data losses. 
Pressure drop with the vortex intake (Fig. 6b and d) was typically about $3 \mathrm{kPa}$, remaining within the working range for the entire observation period ( 2 months). The optical signal strength of $\mathrm{CO}_{2}$ with vortex intake was higher and more stable than that of the system with an inline filter.

\subsection{Field maintenance}

In order to further verify the performance of the EC155 system with vortex intake, field maintenance records from the two sites were compared. These maintenance records included the number of maintenance services; downtime due to clogged intake filters; and percentage downtime, defined as a ratio of downtime due to clogged intake to the actual testingperiod duration $\times 100$. Also included are the minimum and average time periods for the intake filter to clog.

A summary of field maintenance at Olympic Park and Badaling Farm is shown in Table 1. The vortex design reduced the number of maintenance services from 15 to 4 at Olympic Park and from 7 to 0 at Badaling Farm. The percentage downtime at Badaling Farm was reduced from $26 \%$ with the original inline filter intake to $0 \%$ with the vortex intake. At Olympic Park the percentage downtime was $31 \%$ for the inline filter and $5 \%$ for vortex intake. The percentage downtime reflects not just the number of times the filter was clogged, but also how soon the filter was replaced after it clogged. The minimum and average clog times, shown in the last two columns of Table 1, highlight the reduced maintenance requirement of the vortex intake design. At Olympic Park, the inline filters clogged in as little as 1 day, with an average clog period of just 6 days. The minimum maintenance interval for the vortex intake was 21 days, with an average of 46 days. At Badaling Farm, inline filters clogged within as few as 9 days with an average of 20 days, while the vortexintake design required no maintenance for an entire period of 122 days.

Independent of high or low haze cover, the maintenance required for the vortex-intake EC system was markedly reduced, thus decreasing overall downtime substantially. Overall, the vortex intake can improve long-term monitoring of $\mathrm{CO}_{2}$ and $\mathrm{H}_{2} \mathrm{O}$ fluxes in conditions of high particulate concentration.

\section{Conclusions}

The vortex intake significantly reduced maintenance requirements and downtime for a closed-path eddy-covariance system compared to the original inline filter design. The vortex intake eliminated the need for an inline filter in the sample path and kept the sample cell windows clean, preserving the optical signal strength of $\mathrm{CO}_{2}$ and sustaining an acceptable sample cell differential pressure over a much longer period. Although the vortex intake at the Badaling Farm site required no bypass filter replacement during the study period, the by- pass filter at the Olympic Park site clogged, on average, every 46 days. A follow-up experiment is planned to replace the bypass filter with a much larger one to try to extend the maintenance interval even further. There was no significant attenuation of high frequencies compared to the system with an inline filter. The vortex intake helped to overcome shortcomings associated with traditional inline filter systems in extremely polluted conditions. The vortex-intake design extends the geographical application of the EC technique in ecology and allows investigators to acquire more accurate and continuous measurements of trace-gas fluxes in a wider range of ecosystems.

Our results indicate that the vortex intake works better than an inline filter in very polluted urban environments. However, the characteristics of dust differ across ecosystems. Additional long-term studies are therefore needed to evaluate the vortex-intake performances in a variety of ecosystems (e.g., forests, grasslands and deserts). Our study tested the system frequency response at low wind speed above forests, where the frequencies of turbulent fluctuations tend to be low; thus future studies should verify the system frequency response in conditions of higher-frequency turbulence. Sideby-side comparisons of vortex and inline filter designs would also be of value, particularly with the inclusion of IRGAs from other manufacturers and analyzers for other trace gases such as nitrous oxide or methane.

Data availability. All data can be found in the Supplement.

\section{The Supplement related to this article is available online at doi:10.5194/amt-10-1259-2017-supplement.}

Competing interests. The authors declare that they have no conflict of interest.

Acknowledgements. The research was supported by grants from National Natural Science Foundation of China (NSFC; 31670710 , 31670708, 31361130340, 31270755) and the Fundamental Research Funds for the Central Universities (Proj. no. 2015ZCQSB-02). The US-China Carbon Consortium (USCCC) supported this work via helpful discussions and the exchange of ideas. The authors acknowledge Karen Wolfe for technical writing and editing support, Campbell Scientific, Inc. Logan, UT, USA and Wenqing $\mathrm{Hu}$ and Xiaojie Zhen, BTS, Beijing, China. We are grateful to Cai Ren and Cai Zhang for their assistance with the field measurements and instrumentation maintenance. We also would like to thank anonymous reviewers and the editors for their constructive comments on this manuscript.

Edited by: C. Ammann

Reviewed by: M. Aubinet and two anonymous referees 


\section{References}

Aubinet, M., Grelle, A., Ibrom, A., Rannik, Ü., Moncrieff, J., Foken, T., Kowalski, A. S., Martin, P. H., Berbigier, P., Bernhofer, Ch., Clement, R., Elbers, J., Granier, A., Grünwald, T., Morgenstern, K., Pilegaard, K., Rebmann, C., Snijders, W., Valentini, R., and Vesala, T.: Estimates of the Annual Net Carbon and Water Exchange of Forests: The EUROFLUX Methodology, Adv. Ecol. Res., 30, 113-175, 2000.

Aubinet, M., Joly, L., Loustau, D., De Ligne, A., Chopin, H., Cousin, J., Chauvin, N., Decarpenterie, T., and Gross, P.: Dimensioning IRGA gas sampling systems: laboratory and field experiments, Atmos. Meas. Tech., 9, 1361-1367, doi:10.5194/amt-91361-2016, 2016.

Baldocchi, D. D.: Assessing the eddy covariance technique for evaluating carbon dioxide exchange rates of ecosystems: past, present and future, Glob. Change Biol., 9, 479-492, 2003.

Brach, E. J., Desjardins, R. L., and St. Amour, G. T.: Open path $\mathrm{CO}_{2}$ analyzer, J. Phys. E Sci. Instrum., 14, 1415-1419, 1981.

Bressi, M., Sciare, J., Ghersi, V., Bonnaire, N., Nicolas, J. B., Petit, J.-E., Moukhtar, S., Rosso, A., Mihalopoulos, N., and Féron, A.: A one-year comprehensive chemical characterisation of fine aerosol $\left(\mathrm{PM}_{2.5}\right)$ at urban, suburban and rural background sites in the region of Paris (France), Atmos. Chem. Phys., 13, 78257844, doi:10.5194/acp-13-7825-2013, 2013.

Brown, S., Sargent, S., Machado, P., Freemantle, V., Carvalho de Sena Rabelo, L., and Wagner-Riddle, C.: Comparison of $\mathrm{N}_{2} \mathrm{O}$ fluxes measured using flux-gradient, eddy-covariance, and chamber methods from an agricultural site, AGU Fall Meeting 2015, Poster B11B-0426, 2015.

Burba, G. G., Mcdermitt, D. K., Anderson, D. J., Furtaw, M. D., and Eckles, R. D.: Novel design of an enclosed $\mathrm{CO}_{2} / \mathrm{H}_{2} \mathrm{O}$ gas analyser for eddy covariance flux measurements, Tellus B., 62, 743-748, 2010.

Burgon, R., Sargent, S., and Conrad, B.: Performance evaluation of an innovative sampling system for closed path eddy covariance measurements, AMS 32nd Conference on Agricultural and Forest Meteorology, Poster 140, 2016.

Clement, R. J., Burba, G. G., Grelle, A., Anderson, D. J., and Moncrieff, J. B.: Improved trace gas flux estimation through IRGA sampling optimization, Agr. Forest. Meteorol., 149, 623-638, 2009.

Detto, M., Verfaillie, J., Anderson, F., Xu, L., and Baldocchi, D.: Comparing laser-based open- and closed-path gas analyzers to measure methane fluxes using the eddy covariance method, Agr. Forest. Meteorol., 151 1312-1324, 2011.

Eugster, W., Zeyer, K., Zeeman, M., Michna, P., Zingg, A., Buchmann, N., and Emmenegger, L.: Methodical study of nitrous oxide eddy covariance measurements using quantum cascade laser spectrometery over a Swiss forest, Biogeosciences, 4, 927-939, doi:10.5194/bg-4-927-2007, 2007.

Goulden, M. L., Munger, J. W., Fan, S.-M., Daube, B. C., and Wofsy, S. C.: Measurements of carbon sequestration by long term eddy covariance: methods and a critical evaluation of accuracy, Glob. Change Biol., 2, 169-182, 1996.

Hasheminassab, S., Daher, N., Ostro, B. D., and Sioutas, C.: Longterm source apportionment of ambient fine particulate matter (PM2.5) in the Los Angeles Basin: A focus on emissions reduction from vehicular sources, Environ. Pollut., 193, 54-64, 2014.
Ibrom, A., Dellwik, E., Flyvbjerg, H., Jensen, N. O., and Pilegaard, K.: Strong low-pass filtering effects on water vapour flux measurements with closed-path eddy correlation systems, Agr. Forest. Meteorol., 147, 140-156, 2007.

Jia, X., Zha, T. S., Wu, B., Zhang, Y. Q., Chen, W. J., Wang, X. P., Yu, H. Q., and He, G. M.: Temperature response of soil respiration in a Chinese pine plantation: hysteresis and seasonal vs. diel $\mathrm{Q}_{10}$, Plos One, 8, e57858, doi:10.1371/journal.pone.0057858, 2013.

Kroon, P. S., Hensen, A., Jonker, H. J. J., Zahniser, M. S., van't Veen, W. H., and Vermeulen, A. T.: Suitability of quantum cascade laser spectroscopy for $\mathrm{CH}_{4}$ and $\mathrm{N}_{2} \mathrm{O}$ eddy covariance flux measurements, Biogeosciences, 4, 715-728, doi:10.5194/bg-4715-2007, 2007.

Laubach, J. and Teichmann, U.: Measuring energy budget components by eddy correlation: Data corrections and application over low vegetation, Contrib. Atmos. Phys., 69, 307-320, 1996.

Lee, X., Massman, W. J., and Law, B. E.: Handbook of Micrometeorology: A Guide for Surface Flux Measurement and Analysis, Kluwer Academic Publishers, 2004.

Leuning, R. and Judd, M. J.: The relative merits of open- and closed-path analysers for measurement of eddy fluxes, Glob. Change Biol., 2, 241-253, 1996.

Leuning, R. and King, K. M.: Comparison of eddy-covariance measurements of $\mathrm{CO}_{2}$ fluxes by open- and closed-path $\mathrm{CO}_{2}$ analysers, Bound.-Lay. Meteorol., 59, 297-311, 1992.

Massman, W. J.: A simple method for estimating frequency response corrections for eddy covariance systems, Agr. Forest. Meteorol., 104, 185-198, 2000.

McHale, M. R., McPherson, E. G., and Burke, I. C.: The potential of urban tree plantings to be cost effective in carbon credit markets, Urban For. Urban Gree., 6, 49-60, 2007.

Mitchell, S. R., Emanuel, R. E., and Mcglynn, B. L.: Landatmosphere carbon and water flux relationships to vapor pressure deficit, soil moisture, and stream flow, Agr. Forest. Meteorol., 208, 108-117, 2015.

Montgomery, R. B.: Vertical Eddy Flux of Heat in the Atmosphere, J. Atmos. Sci., 5, 265-274, 1948.

Pataki, D. E., Alig, R. J., Fung, A. S., Golubiewski, N. E., Kennedy, C. A., McPherson, E. G., Nowak, D. J., Pouyat, R. V., and Romero Lankao, P.: Urban ecosystems and the North American carbon cycle, Glob. Change Biol., 12, 2092-2102, 2006.

Peltola, O., Mammarella, I., Haapanala, S., Burba, G., and Vesala, T.: Field intercomparison of four methane gas analyzers suitable for eddy covariance flux measurements, Biogeosciences, 10 , 3749-3765, doi:10.5194/bg-10-3749-2013, 2013.

Runkle, B. R., Wille, C., Gažovič, M., and Kutzbach, L.: Attenuation correction procedures for water vapour fluxes from closedpath eddy-covariance systems, Bound.-Lay. Meteorol., 142, 401423, 2012.

Sargent, S.: Quantifying Frequency Response of a Low-power, Closed-path $\mathrm{CO}_{2}$ and $\mathrm{H}_{2} \mathrm{O}$ Eddy-covariance System, available at: http://s.campbellsci.com/documents/us/technical-papers/ cpec200_frequency_response.pdf (last access: 28 March 2017), 2012.

Schotanus, P., Nieuwstadt, F. T. M., and De Bruin, H. A. R.: Temperature measurement with a sonic anemometer and its application to heat and moisture fluxes, Bound.-Lay. Meteorol., 26, 81-93, 1983. 
Shoemaker, W. B., Anderson, F., Barr, J. G., Graham, S. L., and Botkin, D. B.: Carbon exchange between the atmosphere and subtropical forested cypress and pine wetlands, Biogeosciences, 12, 2285-2300, doi:10.5194/bg-12-2285-2015, 2015.

Somers, J. and Sargent, S.: A Novel Low-Power, HighPerformance, Zero-Maintenance Closed-Path Trace Gas Eddy Covariance System with No Water Vapor Dilution or Spectroscopic Corrections, AGU Fall Meeting 2015, Poster B33C-0668, 2015.

Villalobos, A. M., Barraza, F., Jorquera, H., and Schauer, J. J.: Chemical speciation and source apportionment of fine particulate matter in Santiago, Chile, 2013, Sci. Total Environ., 512513, 133-142, 2015.

Wang, Y., Hu, C., Dong, W., Li, X., Zhang, Y., Qin, S., and Oenema, $\mathrm{O}$.: Carbon budget of a winter-wheat and summer-maize rotation cropland in the North China Plain, Agr. Ecosyst. Environ., 206, 33-45, 2015.

Xie, J., Jia, X., He, G., Zhou, C., Yu, H., Wu, Y., Bourque, C., Liu, H., and Zha, T.: Environmental control over seasonal variation in carbon fluxes of an urban temperate forest ecosystem, Landscape Urban Plan., 142, 63-70, 2015.

Yang, Y., Liu, X., Qu, Y., Wang, J., An, J., Zhang, Y., and Zhang, F.: Formation mechanism of continuous extreme haze episodes in the megacity Beijing, China, in January 2013, Atmos. Res., 155, 192-203, 2015.
Yu, L. D., Wang, G. F., Zhang, R. J., Zhang, L. M., Song, Y., Wu, B. B., Li, X. F., An, K., and Chu, J. H.: Characterization and Source Apportionment of PM2.5 in an Urban Environment in Beijing, Aerosol. Air Qual. Res., 13, 574-583, 2013.

Zha, T., Barr, A. G., van der Kamp, G., Black, T. A., McCaughey, J. H., and Flanagan, L. B.: Interannual variation of evapotranspiration from forest and grassland ecosystems in western canada in relation to drought, Agr. Forest Meteorol., 150, 1476-1484, 2010.

Zhang, Y., Huang, W., Cai, T., Fang, D., Wang, Y., Song, J., Hu, M. and Zhang, Y.: Concentrations and chemical compositions of fine particles (PM) during haze and non-haze days in Beijing, Atmos. Res., 174, 62-69, 2016.

Zheng, G. J., Duan, F. K., Su, H., Ma, Y. L., Cheng, Y., Zheng, B., Zhang, Q., Huang, T., Kimoto, T., Chang, D., Pöschl, U., Cheng, Y. F., and He, K. B.: Exploring the severe winter haze in Beijing: the impact of synoptic weather, regional transport and heterogeneous reactions, Atmos. Chem. Phys., 15, 2969-2983, doi:10.5194/acp-15-2969-2015, 2015. 